\title{
El tratado musical de Pedro Martínez de Osma, un testimonio recuperado del siglo XV
}

\author{
Pedro Martínez de Osma's Treatise on Music: \\ A Recovered Testimony from the Fifteenth Century
}

Este artículo presenta un nuevo tratado musical español del siglo XV escrito por Pedro Martínez de Osma, catedrático de Teología en la Universidad de Salamanca. De esta obra se tenía noticia por referencias coetáneas debidas a su colega Ramos de Pareja, pero hasta ahora no se había identificado. Este texto, escrito en 1465 y conservado en la Biblioteca Nacional de Nápoles, permite obtener nueva información de un periodo muy poco explorado en cuanto al pensamiento musical en España, precisamente por la ausencia de fuentes documentales. Analizando su contenido se detalla el ambiente reformista y prehumanista que se vivía en esos años en el Estudio salmantino y se perfila la corriente de pensamiento que, pasando por Ramos y otros autores en torno al 1500, llevarán al florecimiento de los insignes autores del quinientos, en especial Francisco Salinas.

Palabras clave: Pedro Martínez de Osma, Universidad de Salamanca, Ramos de Pareja, teoría musical, Renacimiento español, Humanismo.

This article presents a new fifteenth-century Spanish music treatise written by Pedro Martínez de Osma, Professor of Theology at the University of Salamanca. This text was known through contemporary references by his colleague Ramos de Pareja, but had not been identified until now. Written in 1465 and preserved at the Biblioteca Nazionale Vittorio Emanuele III in Naples, the text provides new information from a very little explored period in Spain in terms of music philosophy, precisely because of the lack of documentary sources. By analysing its content, the author explains the reformist and pre-humanist climate that characterized those years in Salamanca, and outlines the school of thought that would allow distinguished theorists of the sixteenth century century to flourish in the wake of Ramos and other composer-theorists around 1500, especially Francisco Salinas.

Keywords: Pedro Martinez de Osma, University of Salamanca, Ramos de Pareja, music theory, Spanish Renaissance, Humanism.

En 1482, el músico y teórico Ramos de Pareja, publicaba en Bolonia el primer tratado musical impreso de un autor español, titulado Musica practica ${ }^{1}$. Ramos, nacido en Baeza unos cuarenta años antes, debió cursar estudios en la Universidad de Salamanca, donde viviría los turbulentos años finales del reinado de Enrique IV de Castilla, antes de que le sucediese en el trono su hermanastra, la infanta Isabel. Una sucesión complicada por la

${ }^{1}$ Musica practica, Bolonia, Baltasar de Hiriberia, 1482. Hay edición de Johannes Wolf: Musica Practica Bartholomei Rami de Pareja, Leipzig, Breitkopf \& Härtel, 1901. 
guerra entre los partidarios de Isabel y los que apoyaban a la hija del difunto rey, Juana, conocida por mal nombre, como La Beltraneja.

Se tiene noticia de la estancia de Ramos en Salamanca solo por las referencias en su tratado y por alguna noticia posterior de su discípulo Giovanni Spataro. En cierto modo, Ramos debió ejercer la docencia musical en el contexto salmantino, allá por los años 1460 y 1470, donde escribió otro tratado en castellano, perdido por el momento. Además, participó activamente en la vida académica de la Universidad, a tenor de sus disputas con los miembros del claustro, pues al parecer su dificil carácter era bastante dado a la controversia, como demostraría más tarde en su exilio italiano. Las discusiones de Ramos en Salamanca implicaron a personajes de la más alta jerarquía académica, incluyendo al catedrático de Teología, Pedro Martínez de Osma. Según relata Ramos, estando en Salamanca, mantuvieron una disputa a propósito de un tratado musical que el teólogo había redactado. Dice así:

Este Maestro de Osma, ya mencionado, dice: estas tres propiedades, es decir becuadro duro, bemol y natura, tienen tres géneros como los tres géneros melódicos que establece Boecio, es decir, diatónico, cromático y enarmónico; el diatónico, que es algo más duro, dice poseer parecido con el becuadro. El enarmónico, que más se ajusta a lo blando, se compara al bemol. El cromático, por hallarse entre los otros dos, aparenta la imagen de natura. Esto ya, cuando en el estudio salmantino enseñábamos, lo rebatimos en su presencia, y en un tratado en lengua materna que escribimos allí sobre el tema, ya le refutamos en todo, por lo que él, visto y examinado mi tratado dijo:"No estoy yo tan familiarizado con Boecio como este". Pues fui yo quien probó que en los otros dos géneros hay becuadro y bemol como en este. Igualmente, no dudo realmente en hallar en ellos el tetracordio synemmenon, una parte en ellos y otra en estos $^{2}$.

Como se verá, en el nuevo tratado que presentamos aquí, la aparente crítica de Ramos no sería del todo cierta, pues Pedro de Osma sí acaba diferenciando en su tratado los géneros boecianos de los gregorianos. Pero Ramos no duda en atribuirse el mérito y presumir de que el maestro de Osma terminó por reconocer la superioridad de los conocimientos musicales de su antagonista ${ }^{3}$.

2 "Praeterea iste magister Osmensis iam allegatus dicit: istae tres proprietates scilicet a durum, b molle et natura sic se habent sicut illa tria genera melorum, quae ponuntur a Boetio scilicet: diatonicum, chromaticum et enharmonium, quoniam diatonicum, quod aliquantulum durins est, dicit quadrati similitudinem tenere, enharmonium vero, quod magis ad molle coaptatum est, b molli comparat, chromaticum vero, quod inter utrumque medium tenet, naturae imaginem servat. Hoc autem iam, cum in studio legeremus Salmantino, praesente et coram eo redarguimus et in tractatu, quem ibi in hac facultate lingua materna composuimus, ipsi momnibus contradiximus adeo, ut ipse viso et examinato tractatu meo hoc dixerit: Non sum ego adeo Boetio familiarjs sicut iste. Nam ego quidem probavi in duobus aliis generibus esse durum et b molle sicut in isto. Ibidem enim tetrachordum synemmenon reperiri non dubito et alia partitio illorum est, alia vero istius". Musica practica, I.II.6.

${ }^{3}$ Años más tarde, el teórico italiano Franchino Gafurio no dudó en burlarse de la prepotencia del español, por presumir de su victoria dialéctica sobre Pedro de Osma, y así lo dejó anotado en los már- 
La dedicación de Pedro Martínez de Osma a la música en Salamanca ha sido en cualquier caso un asunto poco claro, pues solo contábamos con esta noticia de Ramos de Pareja, además de una cita de Domingo Marcos Durán en su tratado de 1492 Comento sobre lux bella y otra de Alonso Spañon en su Introducción muy útil e breve de canto llano de 15045. También se sabe por su testamento que, a su fallecimiento, conservaba en su poder un monocordio que dejó en herencia a su sobrino Cristóbal, instrumento propio de los músicos pero ajeno a la actividad de un teólogo ${ }^{6}$. Esta era toda la información que relacionaba a Martínez de Osma con la música, hasta la recuperación del manuscrito musical que hoy presentamos, la primera fuente documental directa que corrobora la actividad del teólogo en el campo del pensamiento musical.

\section{Pedro de Osma, teólogo de la Universidad de Salamanca}

Pedro Martínez debió nacer en la diócesis de Osma (Soria) hacia 14277. En mayo de 1444 iniciaba sus estudios en el Colegio de San Bartolomé en Salamanca, aunque poco se conoce de estos años iniciales de su formación. Consta que obtuvo el Magisterio en Artes en 1457, impartiendo a partir de ese mismo año clases desde la cátedra de Filosofía Moral de la Universidad salmantina. Discípulo de Alonso Fernández de Madrigal, "el Tostado" (c. 1401-1455), continuó con los estudios teológicos hasta ocupar el 12 de junio de 1463 la prestigiosa cátedra de Prima de Teología, que obtuvo en disputa con el franciscano Pedro de Caloca (a la postre adversario suyo en su ulterior juicio y condena eclesiástica) sucediendo a los dominicos Lope de Barrientos y Álvaro de Osorio ${ }^{8}$. En esos años fue también nombrado

genes del ejemplar del Musica practica que le había prestado el propio Spataro: "Hic se multum iactat auctor" (Musica practica, ed. J. Wolf, p. 43).

${ }^{4}$ Domingo Marcos Durán: Comento sobre Lux bella, Salamanca, [Juan de Porras], 1498, f. e vv donde el nombre del Magister Petrus de Osma aparece al final del tratado, en una larga lista de autoridades, precediendo justamente a Bartolomé de Pareja, como indicio de su proximidad no solo geográfica (el contexto de la universidad salmantina), sino personal.

${ }^{5}$ Publicada en Sevilla c. 1499, la cita a "el Maestro de Osma" aparece en el capítulo séptimo, "De los géneros", dando la definición inicial: "Género es un común que contiene toda la diversidad de los sonidos, según el Maestro de Osma en su tratado de música. Son tres, a saber, cromático, diatónico, enarmónico, según el Boecio libro primero, capítulo XXI".

${ }^{6}$ Junto con cinco mil maravedís, una ballesta y "un arca de las pequeñas". Véase Florencio Marcos: "Algunos datos biográficos y testamento del Maestro Pedro Martínez de Osma", Salmanticensis, 2, 3, 1995, p. 696.

${ }^{7}$ Ramón Gonzálvez: "Las bulas de la catedral de Toledo", Toletum, 18, 1986, p. 53. Entre la bibliografía dedicada a este autor, en constante aumento en los últimos años, destaca el número especial de la revista Celtiberia, 30, 1980, dedicado a Pedro de Osma († 1480): Homenaje en el V centenario de su muerte.

${ }^{8}$ Gonzalo Díaz: Hombres y documentos de la filosofía española, vol. 5, Madrid, CSIC, 1995, p. 277. José Luis Fuertes: "Contra el nominalismo", Revista Española de Filosofía Medieval, 11, 2004, p. 245. 
canónigo de Córdoba y racionero de la catedral de Salamanca ${ }^{9}$. En el alto puesto académico de catedrático de Prima de Teología mantuvo una intensa actividad y gozó de gran prestigio, hasta que la publicación en 1476 de un problemático texto negando el poder de la confesión y la penitencia o de las indulgencias, en la salvación de las almas (Tractatus de confessione, hoy perdido $^{10}$ ), o cuestionando la infalibilidad de la Iglesia de Roma (que no de la fe católica), le llevó a ser condenado por primera vez en Zaragoza en 1478 , declarándose herética y escandalosa su obra ${ }^{11}$. A esta primera condena siguió otra in absentia el 24 de mayo de 1479 tras un proceso canónico en Alcalá de Henares, convocado por el arzobispo de Toledo Alonso Carrillo como su principal instigador, tras la denuncia de algunos profesores salmantinos. Entre los que declararon en su contra, se encontraba Pedro de Caloca (su antiguo oponente en el acceso a la cátedra de Teología) y el dominico Pedro de Ocaña, dos profesores a quienes en los años previos había fustigado con burlas, acusándoles de "príncipes de los verbosistas" o "vociferadores", por sus posiciones dialécticas y antitomistas ${ }^{12}$. Con esta condena se ordenó la quema de sus escritos sobre las confesiones, "fasta convertirse en çenizas" 13 , y Pedro de Osma se vio obligado a abjurar y acatar la autoridad papal. Esto se llevó a cabo el 29 de junio de 1479 en el

José Labajos Alonso: "Pedro de Osma, impulsor del humanismo", Cuadernos Salmantinos de Filosofía, 22, 1995, p. 142. Vicente Beltrán de Heredia: Cartulario de la Universidad de Salamanca, vol. 2, Salamanca, Universidad de Salamanca, 1970, p. 241. Martínez de Osma fue el único catedrático de Prima de Teología en Salamanca a lo largo del siglo XV que no provenía del convento dominico de San Esteban de la misma ciudad. Véase Ana Cebeira, en su edición de Petri Osmensis in libros Aristotelis comentarii, Pamplona, Universidad de Navarra, 2002, p. 17.

9 F. Marcos: "Algunos datos biográficos...", p. 692. También se postuló en 1471 para una canonjía en Toledo, que por razón desconocida no llegó a obtener. R. Gonzálvez: "Las bulas...", p. 53.

${ }^{10}$ No obstante, su contenido se entresaca en parte de diversas refutaciones al texto que escribió el dominico Juan López de Salamanca. Véase la edición de las mismas por Ramón Hernández: La confesión y las indulgencias, pre reforma y tradición, Salamanca, San Esteban, 1978. No hay certeza de que el polémico libro de Pedro de Osma fuese efectivamente impreso, aunque en la documentación conservada relativa al proceso abunda la expresión "publicada" en referencia a esta obra.

${ }^{11}$ En el contexto inquisitorial, "escandalosa" era aquella idea u opinión que pudiese inducir a error doctrinal, peligrosas para la integridad espiritual del oyente y opuestas a los postulados aceptados en materia de fe. En el Diccionario de Autoridades (1732) se equiparaba a la "ruina espiritual". Véase Antonio de Nebrija: Apología, estudio de Pedro Martín, ed. y trad. de Baldomero Macías, Huelva, Universidad de Huelva, 2014, p. 28. Ese mismo año de 1478 se declaró a Pedro de Osma jubilado en el mes de julio, por haber cumplido los 20 años de magisterio establecidos en los Estatutos de la Universidad. Véase F. Marcos: "Algunos datos...", p. 692.

12 José Luis Fuertes y Federico Panchón (trad.): "Respuesta a algunos disparates de dos verbosistas de esta época", Revista Española de Filosofía Medieval, 11, 2004, p. 312. Ambos llegaron a acusar de heréticas a las ideas de Pedro de Osma, entre otras cosas, pero el Maestro no fue declarado finalmente hereje porque "no fue pertinaz". Véase Juan Tejada: Colección de cánones y de todos los concilios de la Iglesia española, tomo V, Madrid, 1863, p. 30.

${ }^{13}$ F. Marcos: "Algunos datos biográficos...", p. 705; R. Gonzálvez: "Las bulas...", p. 55; V. Beltrán: Cartulario..., p. 166. También en la hoguera se ordenó hacer desaparecer los documentos redactados en defensa de Pedro de Osma, ver José Goñi: "Estado actual de los estudios sobre Pedro Martínez de 
monasterio de San Francisco de Alcalá, tras solemne procesión por la villa "con un hacha encendida en la mano", siéndole prohibida la entrada en Salamanca durante un año ${ }^{14}$. No llegó el maestro de Osma a superar el destierro impuesto, pues falleció en Alba de Tormes el 16 de abril de 1480.

La dedicación de Pedro de Osma en Salamanca a la teología contemporánea y sus problemas, inseparables en sus años de la realidad social del momento, se incardinó siempre en el contexto que le tocó vivir, pues "en aquel momento, la cuestión teológica fundamentaba muchos procesos políticos y se veía refrendada por ellos" 15 . Como elemento central de su producción intelectual, anclada en un firme anti-nominalismo y una precoz defensa del tomismo, Pedro Martínez impartió desde su cátedra nociones guiadas por lo que hoy se ha venido a enmarcar en un "humanismo comunitario y participativo" 16 , que motivó sus críticas a la dialéctica y a aquellos a los que tildaba de "verbosistas", "viles", "fumosistas" o "vociferadores" 17 y le impulsó a cuestionar el papel intermediario de las instituciones eclesiásticas en asuntos de candente actualidad entonces, en especial las ya señaladas indulgencias o la penitencia. No con ánimo revolucionario, ni herético, sino precisamente como producto del impulso, moderno en su reformismo, que remite a las fuentes originales, a la autoridad de los doctores antiqui, y que se revela en su atención al correcto uso que se hiciera desde las instituciones eclesiásticas del poder que la fe les otorgaba, tanto el poder sacramental del papa como el del clero o aquel que recibiese la monarquía por investidura divina ${ }^{18}$.

Osma", Celtiberia, 30, 1980, p. 9; Isabella Iannuzzi: "La condena a Pedro Martínez de Osma", Investigaciones históricas: Época moderna y contemporánea, 27, 2007, p. 26.

${ }^{14} \mathrm{~J}$. Tejada: Colección de cánones..., p. 64; Pablo Luis Alonso Baelo: "El pensamiento de Martínez de Osma", Azafea; revista de filosofía, 12, 2010, p. 174. El testimonio de la quema del Tractatus de confessione en V. Beltrán: Cartulario..., p. 80. No solo tuvo que retractarse el maestro de Osma: también aquellos que en el juicio se atrevieron a defenderle, como Diego de Deza, Fernando de Roa y los licenciados Quintanapalla y Enciso. J. Tejada: Colección de cánones..., pp. 43-44.

${ }^{15}$ P. L. Alonso Baelo: "El pensamiento de Martínez de Osma", p. 201; Melquiades Andrés Martín: "Antiverbosismo en Pedro Martínez de Osma", Celtiberia, 30, 1980, p. 132 y ss.

${ }^{16}$ Cirilo Flórez: "El humanismo cívico castellano: Alonso de Madrigal, Pedro de Osma y Fernando de Roa", Res publica: revista de filosofía politica, 18, 2007, p. 127. También José Labajos Alonso: "Pedro de Osma, impulsor del humanismo y del conocimiento de Aristóteles en Salamanca", Cuadernos Salmantinos de Filosofía, 22, 1995 p. 137 y ss.; José Luis Fuertes: "Pensamiento y filosofía en la Universidad de Salamanca del siglo XV y su proyección en el XVI", Salamanca y su universidad en el primer Renacimiento, siglo XV, Luis E. Rodríguez-San Pedro y Juan Luis Polo (eds.), Salamanca, Universidad de Salamanca, 2010, p. 216. Aunque este humanismo lo matiza, en su aspecto lingüístico y literario, su propio alumno Antonio Nebrija, cuando afirma acerca del maestro de Osma: "en decir sabía poco". Véase J. Goñi: op. cit.

${ }^{17}$ En especial, los citados Pedro de Caloca y Pedro de Ocaña (de quienes hacía mofa como "Licet Loca” y "¡Oh, Caña!"). J. Labajos Alonso: "Pedro de Osma, impulsor...", p. 143; J. L. Fuertes y F. Panchón: "Respuesta a algunos disparates...", pp. 311-312; José Labajos: Escritos académicos de Pedro de Osma, Salamanca, Universidad Pontificia, 2010, p. 28 y ss. Este autor recuerda que loca era la expresión usada para referirse al retrete.

18 Véase I. Iannuzi: "La condena...", p. 41; R. Gonzálvez: "Las bulas...", p. 56; J. Labajos: Escritos académicos..., p. 30; Horacio Santiago-Otero: Fe y cultura en la Edad Media, Madrid, CSIC, 1988, 


\section{El tratado musical en la obra de Pedro Martínez de Osma}

La condena que sufrió Pedro de Osma relegó en los siglos siguientes su producción escrita a la marginalidad de la historia teológica tardo medieval, cuando no al olvido más o menos intencionado, a pesar de ostentar el honor de ser el primer teólogo en España que llevó su obra a la imprenta ${ }^{19}$. A partir de los trabajos de Stegmüller, Reinhardt,Vindel, Tejada y Ramiro, Labajos o Goñi Gaztambide ${ }^{20}$, se ha venido avanzando en la recuperación de su obra, de la que se dispone actualmente de diversas repetitiones, sermones, quaestiones, disputas, comentarios, tratados o glosas, que no obstante no deben significar más que una fracción de lo escrito por un autor que gozó de intensa y larga vida académica. Entre los escritos que cabe considerar perdidos, sigue figurando no obstante el ya mencionado Tractatus de confessione. A buen seguro a causa de la condena eclesiástica por la que se obligó a quemar todos sus ejemplares.

Aquí es donde corresponde incluir el tratado musical que presentamos, obra que se consideraba hasta hoy extraviada. Por fortuna no es así, pues hemos localizado una copia manuscrita conservada en el códice VII.C.19 de la Biblioteca Nacional de Nápoles, un volumen facticio datado entre 1470-9021 anteriormente en la Biblioteca Farnese..$^{22}$ La redacción original del tratado finalizó en el mes de agosto de 1465, según consta en el éxplicit que aparece en el fol. 256 . Pedro Martínez, "thelogici et artium proffessor" según figura ${ }^{23}$, redactó el texto "in persona episcopi salmantini”. El tratado aparece redactado en latín, seguido de una traducción

p. 277, establece un paralelismo entre la figura reformadora de Pedro de Osma y la de Pedro Abelardo. Del mismo autor, junto con Klaus Reinhardt: Pedro Martínez de Osma y el método teológico, Madrid, CSIC, 1987, p. 30 y ss. Marcelino Menéndez y Pelayo lo llamó "voz perdida de los wiclefitas y hussitas en España" (Historia de los heterodoxos españoles, vol. 1, p. 812) o incluso "el primer protestante español" (Historia de los heterodoxos españoles, vol. 3, p. 322).

${ }^{19}$ Fueron sus Commentaria magistri Petri de Osoma in Simbolum Quicumque vult, Segovia, Johannes Parix de Heydelberg, quizás después de 1472. Hay facsímil y estudio por Carlos Romero de Lecea: Madrid, Joyas Bibliográficas, 1977. Este libro usa la misma tipografía que el incunable Sinodal de Aguilafuente, y bien pudiera ser incluso anterior al mismo. Véase A. Cebeira: Petri Osmensis..., p. 41.

${ }^{20}$ Véase la bibliografía en José Vicente Frías: "Obras de Pedro Martínez de Osma", Celtiberia, 30, 1980 , p. 41 y ss.

${ }_{21}^{21}$ Tomamos los datos descriptivos del códice de Alfonso Miola: Notizie di manoscritti neolatini. Parte prima, Mss. Francesi, Provenzali, Spagnuoli, Catalani et Portughesi della Biblioteca Nazionale di Napoli, Nápoles, Federigo Furchheim, 1895, p. 79, y de François Fossier: Le Palais Farnèse, Tome III, Fasc. 2 , Roma, École Française, 1982, pp. 352-354.

22 La biblioteca, fundada por Pablo III (Alessandro Farnesio), pasó en 1565 a su nieto Alessandro (duque de Parma), quien la legó a su hijo Eduardo. A mitad del siglo XVII la biblioteca fue trasladada a Parma y en 1736 fue finalmente transferida a Nápoles por Carlos de Borbón (Farnesio por vía materna), al ser nombrado rey de Nápoles. El volumen que nos ocupa se formó en la biblioteca farnesiana al encuadernar una serie de obras copiadas por la misma mano, incluyendo el tratado de Martínez de Osma, junto con otras de otros copistas.

${ }^{23}$ Esta misma es la denominación que se usa para Pedro de Osma en el proceso que al que se sometió: "maestro en santa Theologia e en Artes". Véase J. Tejada: Colección de cánones..., p. 34. 
resumida en castellano. En el éxplicit de la traducción (fol. 264v ) se afirma que el tratado fue primeramente compilado en latín por el Maestro de Osma "en persona del reverendo señor don Gonçalo de Bivero, obispo de Salamanca", y luego puesto en romance a "ruego de Silva" por el copista Gonzalo de Martos, quien lo termina el once de octubre de 1467.

Gonzalo de Vivero, obispo de Salamanca (1447-80) y antiguo catedrático de la universidad, fue un importante personaje en los círculos cortesanos de Juan II y Enrique IV, miembro del Consejo de ambos monarcas y del de los Reyes Católicos. Parece ser el único nombre entre el cabildo catedralicio salmantino relacionable de manera personal y estrecha con el de Martínez de Osma.Ambos fallecieron el mismo año, y en su testamento el obispo menciona un libro de Pedro Martínez: “A Gonzalo de León mando que le paguen lo que le devo de sus escripturas, e el libro por donde escribe es del maestro Osma; mando que se lo devuelvan"24. El libro al que se refiere aquí el obispo no debe ser el tratado musical, por los quince años transcurridos desde la copia del ejemplar conservado en Nápoles. En cuanto al Silva que solicita la traducción al romance del tratado musical, debe tratarse de Tristán de Silva, un músico y teórico calificado por Ramos de Pareja en su Musica practica (I.5) como "familiarissimo nostro"y también "hispano" con quien debió pues coincidir en el estudio salmantino ${ }^{25}$.

El tratado musical se escribió pues en agosto de 1465, año en el que aparecen diversas noticias en las actas de Claustros salmantinas relativas a la actividad académica de nuestro autor. Así, sabemos que fue requerido para que abonase los derechos correspondientes a su nombramiento como maestro en Teología, al parecer todavía pendientes de pago $^{26}$. También ese

\footnotetext{
${ }^{24}$ Florencio Marcos: "Pedro de Osma en la documentación del archivo catedralicio de Salamanca", Celtiberia, 30, 1980, p. 108. El notorio interés del obispo por los libros le señala como destacado mecenas de la biblioteca catedralicia, y explica la polémica originada en 1476 a causa de la erección de la nueva biblioteca universitaria, que Gonzalo de Vivero consideró una amenaza para el palacio episcopal, su importante biblioteca personal y para la Catedral, en especial por causa del prestigio de la sede. Véase Lucía Lahoz: "La imagen de la Universidad de Salamanca en el Cuatrocientos", Salamanca y su Universidad en el Primer Renacimiento; siglo XV, L. E. Rodríguez-San Pedro y J. L. Polo (eds.), Salamanca, Universidad de Salamanca, p. 298. La fecha de la muerte del obispo Vivero es dudosa: su testamento está fechado en 1480, pero en el libro viejo del Cabildo de la catedral se fecha su fallecimiento en 1482. Es pertinente destacar que su criado Fernando de Torrijos fue un frecuente substituto de Martín González de Cantalapiedra en la cátedra de Música de Salamanca, entre 1467 y 1478, sin llegar a ocupar él mismo la citada cátedra, Dámaso García Fraile: "La cátedra de música de la Universidad de Salamanca", Anuario musical, 48, 1991, p. 73. El escribano Gonzalo de León mencionado no debe ser el mismo Gonzalo responsable de la traducción y copia del manuscrito que nos ocupa, puesto que Martos es de la villa de Jaén.

${ }^{25}$ Robert Stevenson: Spanish Music in the Age of Columbus, The Hague, 1960, p. 56. Diogo Barbosa, en su Bibliotheca Lusitana historica, critica, e cronologica de 1752 (vol. III, Lisboa, Ignacio Rodrigues, p. 765), reputa como portugués a este personaje. Véase también Santiago Galán: La teoría del canto de órgano y contrapunto en el Renacimiento español, Madrid, Alpuerto, 2016, p. 100.

${ }^{26}$ José Vicente Frías: "Pedro Martínez de Osma, catedrático salmantino del siglo XV", Celtiberia, 57 , 1979, p. 69. Recordemos que Martínez de Osma apenas llevaba dos años regentando esta cátedra, lo
} 
mismo año fue nombrado contador ${ }^{27}$, y además se le encargó junto con otros doctores del estudio salmantino que dispusieran de dos mil florines para comprar libros para la universidad. Aunque la producción conservada de mano de Pedro Martínez no contiene en general indicación alguna de fecha, casualmente se data en mayo de este 1465 su Repetitio de efficatia legis Christi ${ }^{28}$.

Las noticias conservadas en la documentación universitaria acerca de Pedro de Osma, que no comienzan hasta 1464, no arrojan luz alguna sobre su relación con la música o su implicación en la docencia musical. El profesor de música en la universidad, identificado desde el establecimiento de esta cátedra en el siglo XIII como "maestro de canto de órgano", se debe considerar en estos años un docente principalmente dedicado a la enseñanza de la práctica musical ${ }^{29}$. No sería pues en ningún caso esta una ocupación asignable a Pedro Martínez como Maestro en Artes, y menos posteriormente como catedrático en Teología. Por tanto, el tratado que presentamos no se escribió como texto de trabajo para usar en las clases dictadas por este autor, sino seguramente como material de discusión a requerimiento de otros profesores con los que Pedro Martínez debatía, entre ellos Ramos de Pareja. La disputa entre estos dos pensadores debió producirse entre la escritura del tratado que presentamos y antes de la partida de Ramos a Italia, quizás a finales de los años setenta, donde ya se debía encontrar el teórico de Baeza en el momento de fallecer Pedro de Osma ${ }^{30}$.

\section{Estructura de los dos textos del tratado}

El tratado en latín se copia entre los folios $237^{\mathrm{v}}$ y $256^{\mathrm{v}}$ del códice y se encabeza en tinta roja de la siguiente manera:"Incipit tractatus sive libellus quidam in quo demostratur musicam ecclesiasticam non omnino coartari sub documentis a Boecio traditis et praepositum [...]". El tratado en castellano aparece justo a continuación, entre los folios $256^{\mathrm{v}}$ y el $264^{\mathrm{v}}$, copiado por la misma mano. Su encabezamiento reza: "Comiença el tratado en que se demuestra la musica gregoriana en grand parte ser diversa de la musica

\footnotetext{
que explica que su oponente Pedro de Ocaña le calificase en sus ataques como in teología magister novellus. Véase J. Labajos: Escritos académicos..., p. 26.

${ }^{27}$ Cargo elegido cada 11 de noviembre por el claustro del primicerio (esto es, de los catedráticos) con la misión de revisar las cuentas del administrador (Antonio García: "Consolidaciones del siglo XV", Historia de la Universidad de Salamanca, Luis E. Rodríguez-San Pedro [coords.], vol. I, Salamanca, Universidad de Salamanca, p. 46). Curiosamente, Pedro de Osma como contador debía fiscalizar las actuaciones económicas del administrador, quien a su vez ese año de 1465 debía reclamar al maestro los derechos que adeudaba por su nombramiento (y cobrarle la multa correspondiente llegado el caso).

${ }^{28}$ J. Labajos: Escritos académicos..., p. 38 y ss.

${ }^{29}$ Este asunto lo he desarrollado por extenso en S. Galán: La teoría de canto de órgano..., p. 95 y ss.

${ }^{30}$ Evidentemente, la datación del tratado de Pedro de Osma en 1465 permite considerar esta fecha como límite post quem para la fecha de partida de Ramos hacia Italia, pues este debió conocer el tratado que discutió en persona con Pedro de Osma y menciona en su propia obra.
} 
boeciana". El papel usado presenta filigranas en "tijeras", que indicaría procedencia italiana del material base de copia, lo que no es obstáculo para su presencia en España, pues la misma filigrana aparece en el papel usado en otros volúmenes españoles coetáneos ${ }^{31}$.

En la introducción de ambos textos se anuncia la organización del tratado, que se dividirá en las siete secciones que muestra el Cuadro $1^{32}$.

Cuadro 1. Capitulos en el Tractatus y el Tractado de Pedro de Osma

\begin{tabular}{|c|c|}
\hline monstratur... & Tratado en que se demuestra... \\
\hline $\begin{array}{l}\text { Primum itaque de hiis circa que } \\
\text { frequentibus contingit errare est proprietas } \\
\text { sine genus cantinele. }\end{array}$ & $\begin{array}{l}\text { La primera cosa acerca de la qual } \\
\text { muchas vezes acaece de errar: es la } \\
\text { propiedad del canto. }\end{array}$ \\
\hline Secudum magis atque minus semitonium. & $\begin{array}{l}\text { La segunda el semitono mayor y } \\
\text { menor. }\end{array}$ \\
\hline $\begin{array}{l}\text { Tertium melodica proportio id est ea } \\
\text { proportio in qua consisitit melodia. }\end{array}$ & $\begin{array}{l}\text { La tercera la proporción en que } \\
\text { consiste la melodía. }\end{array}$ \\
\hline Quartum denominatio sive nomen toni. & La quarta este nombre, tono. \\
\hline Quintus numerum tonorum. & $\begin{array}{l}\text { La quinta el cuento o número de los } \\
\text { tonos. }\end{array}$ \\
\hline Sext & La sexta las especies de los tonos. \\
\hline $\begin{array}{l}\text { Septimum consonantie index qui apud } \\
\text { Pithagoram et Boecium dicitur esse magis } \\
\text { intellectus quam sensus. }\end{array}$ & $\begin{array}{l}\text { La séptima es si de la consonancia } \\
\text { deba juzgar el entendimiento según } \\
\text { dixo Boecio y Pitágoras o el sentido } \\
\text { del oír según dizen otros. }\end{array}$ \\
\hline
\end{tabular}

El séptimo y último capítulo se subdivide en el original latino en tres secciones, la primera sobre las proporciones de las voces del canto llano, la segunda encabezada como "de limitibus armonice facultatis", y la tercera como "de indice consonantis", es decir, la cuestión principal del capítulo. Por su parte, los capítulos en la traducción castellana solo se encabezan hasta el cuarto capítulo y luego ya no se distinguen los siguientes si no es porque inician nuevo párrafo, sin mayor señalamiento individual.

El objetivo del tratado tal como se anuncia al principio es demostrar que los modos expuestos por Boecio en su De institutione musica no equivalen a

${ }^{31}$ Estas marcas de agua se referencian como Briquet 10626 en la descripción del volumen de F. Fossier: Le Palais Farnèse, pp. 352-354. Otros manuscritos españoles que las muestran son el Ms d.II.15 del Monasterio del Escorial, de 1462-64, o el Ms 15001 de la Biblioteca de la Fundación Lázaro Galdiano, de 1451-75. Parece pues incorrecto afirmar que el texto fue copiado en Italia por "Gonzalvo de Martino" (nombre que se italianiza innecesariamente), como se afirma en François Fossier, loc. cit.

${ }^{32}$ Como tratado, la sistematización en la exposición de la materia a discutir es característica para este tipo de escritos, que se diferencian así de la tipología de otras obras conocidas del autor. Se tiene noticia de otros dos tratados de Pedro de Osma: el citado Tractatus confessione, desaparecido en la hoguera, y el Tractatus brevi de peccato originali et actuali. Véase J. Labajos: Escritos académicos..., pp. 310-340. 
los usados en el canto llano o gregoriano. Para cumplir tal demostración, el razonamiento comienza definiendo los términos fundamentales que caracterizan el problema a tratar, esto es, aquellos de propiedad, semitono mayor y menor, proporción de la melodía (intervalos) y tono. Una vez aclarados estos conceptos, Pedro de Osma pasa a discutir la cuestión central en que todos ellos confluyen, que es la de caracterizar los modos del canto llano, demostrando a partir de los datos aportados que, en efecto, no son la misma cosa que los boecianos. El séptimo capítulo de ambos tratados, a modo de apéndice, expone un problema fundamental para la práctica del canto, y en especial para el contexto del Renacimiento musical en España como en el resto de Europa, que es determinar la preeminencia del intelecto o del sentido del oído a la hora de valorar la corrección de las consonancias, tanto en el canto llano como en la práctica de la música polifónica.

En suma, partiendo de una exposición ordenada de los conceptos más elementales acerca del tema a discutir, Pedro de Osma avanza al nivel siguiente de organización de tales elementos en unidades superiores (los modos), para acabar ofreciendo una conclusión eminentemente práctica que refiere al problema central en la práctica real del canto, el de juzgar las consonancias sonoras.

\section{La doctrina musical en el tratado de Pedro de Osma}

Para sacar del error en el que, afirma, caen muchos músicos de su tiempo, se argumentan las citadas cuestiones como sigue.

A) Las propiedades del canto y el hexacordo. Martínez de Osma comienza explicando cómo Boecio asigna al canto tres genera ("propiedades" en la versión romance): diatonon, croma y enarmonium, constituidas en sendos tetracordios que se diferencian por su configuración interválica interna ${ }^{33}$. Los intervalos se denominan en la versión castellana "espacios", por lo que cada tetracordio consta de cuatro notas y tres espacios (fol. 257v). El tetracordio diatonon consta de un espacio de semitono y dos de tono. El croma consta de dos de semitono y uno de tres semitonos. El enarmonium consta de dos espacios de medio semitono y uno de dos tonos. Además, según nuestro autor, cada género boeciano se identifica por su "manera de sonar": el primero es duro ("fortis"), el segundo blando ("blandius atque mollius"), el tercero "mediano" ("medium") 34 .

\footnotetext{
${ }^{33}$ Fol. 238. Boecio, en De institutione musica, I.XXI (ed. Godofredus Friedlein, Boetii de institutione arithmetica libri duo, de institutione musica libri quinque, Leipzig, Teubner, 1867), no habla de propiedades, sino de "géneros" diatonum, chroma y enarmonium. A lo largo de la discusión de este nuevo tratado musical español, tendremos que distinguir los términos latinos usados en el original de Pedro de Osma, de aquellos que aparecen en la traducción romance de Gonzalo de Martos, que pueden no ser exactamente coincidentes.

${ }^{34}$ A partir del texto boeciano (loc. cit.), donde se utilizan respectivamente los términos durius, mollius y optime coniunctum. Las mitades de semitono son asimismo denominadas diesi. Abundando
} 
En cuanto a la "música gregoriana", Pedro de Osma identifica también tres propiedades, conocidas como becuadro, bemol y natura, que consisten en sendos hexacordos ("exacor, que quiere dezir seis boces o seis cuerdas") de cinco espacios que abarcan cuatro tonos y medio (fol. $257^{v}$ ). El medio tono se encuentra entre Mi y Fa, y entre las demás voces (ut-re, re-mi, fa-sol, sol-la) hay un tono, por eso afirma que las tres propiedades "proceden en una manera", aunque "son diferentes en la manera del sonar": la primera dura ("forte atque rigidus"), la segunda blanda, la tercera mediana (véase cuadro 2). De esta "pequeña semejanza" avisa Pedro de Osma que parte la confusión entre las propiedades boecianas y las gregorianas, semejanza que el autor refuta fácilmente puesto que se evidencia tanto la diferencia en la conformación interna de intervalos entre tetracordios boecianos y hexacordos, como el diferente número de voces en ambos casos: cuatro en los boecianos por seis en los gregorianos. El razonamiento se amplía en el texto latino con argumentaciones dialécticas que refuerzan estas diferencias ${ }^{35}$.

Cuadro 2. Propiedades boecianas y gregorianas según Pedro de Osma

\begin{tabular}{|l|l|l|c|l|}
\hline & Propiedad & Sonido & Voces & Intervalos \\
\hline \multirow{4}{*}{$\begin{array}{l}\text { Tetracordios } \\
\text { boecianos }\end{array}$} & diatonon & duro & 4 & $1 \mathrm{st}, 2 \mathrm{~T}$ \\
\cline { 2 - 5 } & croma & blando & 4 & $2 \mathrm{st}, 11 / 2 \mathrm{~T}$ \\
\cline { 2 - 5 } & enarmonium & mediano & 4 & $1 / 4 \mathrm{~T}, 1 / 4 \mathrm{~T}, 2 \mathrm{~T}$ \\
\hline \multirow{3}{*}{$\begin{array}{l}\text { Hexacordos } \\
\text { gregorianos }\end{array}$} & becuadro & duro & 6 & $1 \mathrm{st}, 3 \mathrm{~T}$ \\
\cline { 2 - 5 } & bemol & blando & 6 & $1 \mathrm{st}, 3 \mathrm{~T}$ \\
\cline { 2 - 5 } & natura & mediano & 6 & $1 \mathrm{st}, 3 \mathrm{~T}$ \\
\hline
\end{tabular}

más adelante (De institutione musica, V.16) en la discusión basada en Aristoxeno (Harmónica, II.50) Boecio relaciona la "dureza" de un género con la mayor amplitud del intervalo superior del tetracordio, siendo en cambio "blando" el género que presenta menores intervalos. Entre los teóricos españoles, esta diferenciación se traduce en una atención especial al efecto de la alteración descendente bemol sobre las notas que "hacen el punto blando", y del becuadro (asimilable al sostenido actual) que lo hace "recio", como apunta Domingo Marcos Durán (Comento sobre Lux bella, fol. d vi), publicando en Salamanca en 1498, que avisa "mi fortifica, fa mollifica" y "fortificar la voz es hacerla intensa, recia y fuerte; mollificar es hacerla remisa, lasa, blanda, dulce y floja. La sol la sostiene, esto se entiende que has de sostener la ii boz destas tres bozes". Y justo a continuación: "el bemol y el becuadro no está en dezir mi ni $f a$, salvo en la garganta faziendo el punto rezio o blando". Véase S. Galán: La teoría de canto de órgano..., p. 223.

35 "Omne genus ecclesiasticum progreditur per quatuor tonos ac semitonium. Ullusque genus boecianum progreditur per quatuor tonos ac semitonium. Ergo nullum genus boecianum est genus ecclesiasticum" (fol. 239). Pedro de Osma domina pues perfectamente la teoría de las propiedades de las deducciones en el canto, que caracteriza y diferencia por extenso de los genera cantilene boecianos en el texto original latino (fol. 138). 
Es importante destacar el uso en el texto en este punto del término “exacor" en relación a las propiedades. El sistema de organización de las sílabas o voces del gamut en grupos de seis notas se atribuye a Guido de Arezzo, quien en su Epistola ad Michaelem (h. 1032) proponía a partir de estas seis sílabas el inmediatamente exitoso sistema de solmisación sobre el himno a San Juan Bautista Ut queant laxis ${ }^{36}$. No obstante, el monje italiano no usó el término "hexacordo" ni teorizó sobre su naturaleza o su posible transposición a otras notas diferentes del $u t$ o $d o^{37}$. Hasta el momento, se consideraba que era Ramos de Pareja el primer teórico que había usado en 1482 el término "hexachordum" para referirse a las deducciones del sistema guidoniano $^{38}$, pero a la luz de este nuevo texto podemos comprobar que Pedro de Osma lo utilizaba ya veinte años antes. Esto apunta al contexto de la Universidad de Salamanca como aquel donde pudo germinar esta asociación entre el término hexacordo y el de deducción, y donde la aprendería Ramos, como parece apuntar este nuevo tratado ${ }^{39}$. Es de notar que Ramos de Pareja pretendía con su argumentación sobre los hexacordos superar el sistema tradicional de solmisación de Guido de Arezzo ("quizás mejor monje que músico" ${ }^{40}$ ) a favor de su propio sistema basado en la octava, pero Franchino Gafurio aprovechó el nuevo término de hexacordo aportado por Ramos en su tratado y el respeto que podía suscitar esa palabra por su similitud con el antiguo tetrachordum, para argumentar en su Practica musice de 1496 con nuevas fuerzas a favor del sistema tradicional de solmisación por hexacordos que Ramos había pretendido desechar ${ }^{41}$.

${ }^{36}$ Jacques Chailley: "Ut queant laxis' et les Origens de la Gamme”, Acta Musicologica, 56, 1984, p. 48. Por los mismos años, el monje benedictino Hermannus Contractus, en Reichenau, proponía una visión diferente de la unidad de seis notas, entendida como el tetracordio de las cuatro finales del canto ( re, mi fa sol), a las que se añadía una nota a distancia de un tono en ambos extremos. Véase Richard L. Crocker: "Hermann's Major Sixth", Journal of the American Musicological Society, 25, 1972, p. 19.

${ }_{37}$ Guido presenta el sistema, a partir de la sílaba ut, tan solo como una ayuda memorística para entonar melodías desconocidas. Serán otros los autores que inmediatamente ampliarán el sistema a los hexacordos comenzando en la nota sol y en $f a$, y ahondarán a partir del siglo XIII en las implicaciones del sistema respecto al espacio tonal, las mutaciones, etc. Véase S. Galán: La teoría de canto de órgano..., p. 183.

${ }^{38}$ Ramos de Pareja: Musica practica, I.4. El primer autor que realiza una exposición detallada del sistema hexacordal, incluyendo las mudanzas, es Jerónimo de Moravia h. 1272 en su Tractatus de musica, ed. S. M. Cserba, Regensburg, 1935, pp. 46-55, pero no usa el término hexacordo para este asunto, sino que menciona "VI syllabae", utilizando hexachordum sólo en referencia a los instrumentos de seis cuerdas, en una enumeración que abarca desde el monocordo hasta el decachordum (p. 58).

39 Pedro de Osma (más rigurosamente, el romanceador Gonzalo de Martos) solo utiliza el término con este sentido de deducción en este punto de la traducción romance (fol. 257v). En el resto del tratado "hexacordo" se refiere a un intervalo que abarca seis notas, mientras que en el original latino habla siempre de "sex vocibus".

40 Ramos de Pareja: loc. cit.

${ }^{41}$ Véase Stefano Mengozzi: The Renaissance Reform of Medieval Music Theory, Cambridge, University Press, pp. 184, 205; Ann E. Moyer: Musica scientia, Musical Scholarship in the Italian Renaissance, Ithaca, Cornell University Press, p. 55. También S. Galán: La teoría de canto de órgano..., p. 196 y ss. El rechazo de Ramos al sistema de solmisación era un punto de acuerdo con la doctrina de Johannes Galli- 
B) El semitono mayor y menor. La discusión de este tópico central en la tratadística del momento se plasma de manera bien diferente en las dos versiones de nuestro tratado. En el texto en romance, se despacha el asunto en breve espacio, pero con información precisa y bien orientada al aspecto práctico del problema (fol. $257^{\mathrm{v}}$ ). Se informa de la imposibilidad de dividir el tono en dos mitades iguales y se aclara que los semitonos que lo dividen no son mitades de tono, sino partes que no llegan a tono ${ }^{42}$. De aquí resulta un semitono mayor y otro menor que, afirma, algunos músicos de manera errónea asignan en el canto llano al intervalo Mi-Fa (el menor) y el intervalo Fa-Sol (el mayor). Esto, afirma, es falso, pues si fuese verdad, tanto el intervalo de quinta como de octava resultarían menores de lo que Boecio demuestra en su tratado. Destaca que Pedro de Osma ubique la distancia de semitono mayor entre Fa y Sol, que como voces del gamut por supuesto están separadas por un tono. Pero se entiende sin embargo en el contexto del uso común de las conjuntas o notas alteradas en el canto llano y en el contrapunto, muy presente en la tratadística española desde Fernand Estevan en su Arte de canto llano de 1410 hasta las extensas tablas de solmisación para conjuntas de Domingo Marcos Durán en la Sumula de canto de organo de $1503^{43}$. En los textos españoles la conjunta más destacada es precisamente la que se realiza sobre la voz Fa, elevándola para aproximarla medio tono hacia el Sol, el semitono mayor al que hace referencia Pedro de Osma. También se destaca esta misma conjunta en el tratado anónimo de contrapunto contenido en el manuscrito 91 de la catedral de Girona (c. 1400), donde el autor relaciona el semitono mayor, o apotome (término griego que Pedro de Osma utiliza en el redactado latino de su tratado ${ }^{44}$ ) con la distancia que separa el Fa sostenido del Sol${ }^{45}$.

cus, autor que, como vamos a ver en seguida, se relaciona con algunas ideas que desarrolla Pedro de Osma en el nuevo tratado que presentamos.

42 El autor no lo especifica, pero la raíz "semus" en efecto no significa "mitad", sino que hace referencia a la imperfección de la medida de esta distancia, que no llega a un tono.

43 Sobre los diversos aspectos de la teoría de conjuntas véase Oliver Ellsworth: "The Origin of the Coniuncta: A Reappraisal", Journal of Music Theory, 17, 1, 1973, pp. 86-109; Karol Berger: Musica ficta, Theories of Accidental Inflections in Vocal Polyphony from Marchetto Da Padova to Gioseffo Zarlino, Cambridge University Press, 1987, pp. 12, 48, passim; Paloma Otaola: "Les coniunctae dans la théorie musicale au Moyen Age et la Renaissance (1375-1555)", Musurgia, V, 1998, p. 53 y ss.; S. Galán: La teoría de canto de órgano..., p. 186 y ss. Del mismo autor: "Las tábulas de Urrede de Salamanca en su contexto: contrapunto improvisado y teoría musical del siglo XV español en el contexto europeo", Musicología global, musicología local, Madrid, Sociedad Española de Musicología, 2013, p. 1831 y ss.

${ }^{4}$ Siguiendo a Boecio (De institutione musica, II.30), de quien toma también el término diesis para el semitono menor y comma para la distancia en que excede el semitono mayor respecto al menor.

45 "Item ubicumque sexta fieri oporteat super mi vel la de elami graui, que fieri habet jn csolfaut, hoc est super fa, illud fa debet altificari per semitonium maius, quod apotome nuncupatur, et debet signari per signum de \# aut nomen fa, dum tamen per ipsum fa sol, quod est jn dlasolre, sequatur jmmediate, et erit octaua»". Karl-Werner Gümpel y Klaus-Jürgen Sachs: "Das Manuskript Girona 91 Und Sein Contrapunctus-Traktat”, Archiv Für Musikwissenschaft, 45, 3, 1988, p. 195. 
La conclusión a la que llega Pedro de Osma es que solo es admisible la presencia de un semitono menor entre Mi y Fa, sin que el cantor deba preocuparse de la exacta distancia que representa, pues asegura que este es un asunto propio del matemático. Para el cantor eclesiástico la diferencia de semitono menor a mayor es "insensible" y, como ya anticipa aquí Pedro de Osma, los cantantes deben preocuparse solo de los aspectos "sensuales" del canto, no de los intelectuales, argumento que desarrollará por extenso más adelante en el tratado. No obstante, deja claro que los semitonos presentes en los diferentes hexacordos según su propiedad (natura, bemol, becuadro) son, en efecto, sutilmente diferentes, lo que justifica precisamente la existencia de tales propiedades ("en otra manera las propiedades serían vanas", fol. $258^{\mathrm{v}}$ ) y que impide que unas se puedan mudar en otras. Aunque la diferencia que existe entre las propiedades es por tanto real, "quanta sea determinadamente no es cosa sabida" 46 . Estas afirmaciones coinciden perfectamente con el espíritu general de los teóricos españoles de este siglo, sensibles en general a los problemas de la práctica musical y siempre proclives a dedicar más atención a estos que a los aspectos puramente especulativos de la teoría musical ${ }^{47}$.

La extensa discusión de este asunto en el redactado latino del tratado tampoco desarrolla los aspectos matemáticos de la división del tono. Tan solo se indica que la proporción correspondiente al tono es la sesquioctava y se menciona brevemente la demostración boeciana sobre la indivisibilidad del tono en dos partes iguales, sin entrar en demostraciones numéricas, pues según confiesa Pedro de Osma "tractatus de semitonis non parva habere dificultatem" (fol. 242) ${ }^{48}$.

C) Las proporciones en la melodía. En este apartado se defiende que no solo son buenas las proporciones musicales (intervalos) consideradas consonantes desde Pitágoras (diatesarón, diapente, diapasón con diapente, “doblado diapasón"), sino otras utilizadas tanto en el canto llano como en el contrapunto: la segunda, tercera, cuarta, quinta, sexta, séptima y la "ochava". Pedro de Osma, a partir de la autoridad de Ptolomeo ${ }^{49}$, defiende que todas son proporciones útiles para el canto, aunque algunos califiquen a las no pitagóricas como disonantes o "aliquo modo disonantes" (fol. 243). Esto no preocupa a nuestro autor, pues vuelve a aludir a la necesidad de valorar la consonancia según el sentido del oído, remitiendo en este asunto al último apartado del

\footnotetext{
${ }^{46}$ En el texto latino lo expresa: "Sed quantus sit excessus ille quo bquadra excedunt naturata et naturata bmollata, factemur nobis esse ignotum" (fol. 241v).

47 Véase S. Galán: La teoría de canto de órgano..., p. 28 y ss, passim.

48 Véase Boecio: De institutione musica, I:16. También Rowan Atkinson: The Critical Nexus, Oxford, University Press, 2009, p. 20; Amaya García: El Concepto de consonancia en la teoría musical, Salamanca, Publicaciones de la Universidad Pontificia, 2006, p. 191.

49 Siguiendo también el argumento presentado por Boecio: De institutione musica, V.11.
} 
tratado. En el extenso original latino de este capítulo se definen todos los intervalos especificando su configuración en tonos y semitonos. También se citan las divisiones pitagóricas menores que el semitono (comma, schisma, diaschisma ${ }^{50}$ ) y se insiste en la imposibilidad de percibir distancias tan minúsculas, remitiendo en este asunto de nuevo a la discusión final del tratado.

Es interesante la argumentación de Pedro de Osma a favor de incluir en el "cantus planus" tanto al canto monódico, como al de diversas voces: el canto de órgano y el contrapunto ${ }^{51}$. En todos estos casos, afirma, se utilizan las mismas proporciones y consonancias entre voces, pues tanto son consonancias las voces simultáneas del contrapunto, como las sucesivas del canto llano. Además, aclara, tanto el canto llano como el contrapunto se deben calificar como "cantus planus", ya que ambos proceden por "plana sensibilia", esto es, de manera sencilla para los sentidos (fol. 244). Es patente aquí la atención que presta el autor al canto polifónico en su contexto y la autoridad que juzga al oído del cantante para determinar las consonancias apropiadas en la práctica. Es esto algo tan cierto para Pedro de Osma que incluso llega a afirmar que las proporciones pitagóricas se obvian tanto en antiguas como en modernas tradiciones de canto, y se utilizan conjuntamente con las no pitagóricas, en especial cuando se juntan numerosas voces en el canto (fol. 243).

D) Diferencias entre los tonos boecianos y los eclesiásticos. Pedro de Osma se ocupa ya en el problema central que motiva la redacción de su tratado, ocupando en esta discusión desde el capítulo cuarto al sexto ${ }^{52}$. En primer lugar, se define el sentido boeciano del término "tono", que hace referencia exclusivamente a la distancia interválica que hay entre dos voces (notas) en proporción sesquioctava (cuando "una boz tiene a otra en sí e más la ochava della" fol. 257v $)^{53}$. En cambio, en el contexto eclesiástico, el término tono tiene triple significado: significa primero la distancia interválica en el sentido boeciano; en segundo lugar, se usa como alternativa al término "modo", de donde parte la confusión que el autor quiere aclarar, provocada a su entender cuando algunos autores confundieron los ocho modos -tropus ut modus- boecianos (dórico, hipodórico, etc.) con los ocho modos eclesiásticos (fol. 245). En tercer lugar, el término tono se usa para

\footnotetext{
50 Siguiendo a Filolao tal como lo discute Boecio: De institutione musica, III.

${ }^{51}$ La diferenciación en el texto remite al canto polifónico desde música escrita (canto de órgano), diferente del que se realiza improvisadamente (contrapunto). Véase Paloma Otaola: Tradición y modernidad en los escritos musicales de Juan Bermudo: del "Libro primero" (1549) a la "Declaración de instrumentos musicales” (1555), Kassel, Edition Reichenberger, 2000, p. 244 y ss.; S. Galán: La teoría de canto de órgano..., p. 107 y ss, passim.

52 Capítulos que en la traducción castellana se reúnen en un solo apartado.

${ }^{53}$ La discusión del original latino (fol. 239v) remite no solo a los capítulos del De institutione musica de Boecio, sino también al primer libro de la Arithmetica del mismo autor.
} 
diferenciar las voces del canto entre las que no se puede hacer mudanza, como cuando se afirma que "en bfabemi no puede haber mutança, porque el mi es tono et el fa semitono" (fol.260). Destaca la diferenciación que hace entre semitono descendente (de $\mathrm{Fa}$ a $\mathrm{Mi}$ ) y ascendente (de $\mathrm{Mi}$ a $\mathrm{Fa}$ ), al que califica específicamente como subsemitonum (fol.246), denominación usada en tiempos posteriores para identificar la nota situada medio tono por debajo de la finalis del modo, hacia la que en efecto tiende con un movimiento ascendente, a modo de sensible, en la resolución de las cláusulas armónicas. Esta referencia que aparece en el texto de Pedro de Osma, es la cita explícita más antigua del término de la que tenemos noticia ${ }^{54}$.

Las diferencias que demuestran que los tonos boecianos y los eclesiásticos no son los mismos, según detalla Pedro de Osma son, resumidas, las siguientes:

a. los tonos boecianos abarcan hasta quince voces, los eclesiásticos diez o menos ${ }^{55}$

b. los tonos eclesiásticos son especies de octava (más en concreto, del "doblado diapasón") y los otros son especies de diapasón con diapente;

c. los boecianos empiezan por una sola voz, mientras que los eclesiásticos pueden empezar por cuatro o cinco (incluso, aclara, si un tono boeciano se hace comenzar por una nota diferente, se convierte en otro tono distinto);

d. los tonos boecianos comienzan cada uno en una voz más alta que el precedente, mientras que en lo eclesiásticos, esto solo sucede en los tonos "maestros" (los auténticos), no en los "discípulos" (los plagales);

e. los tonos eclesiásticos usan especies o intervalos diferentes de las de los boecianos ${ }^{56}$, luego en definitiva no pueden ser los mismos.

Pedro de Osma evidentemente no agota, ni tan solo profundiza, en el complejo problema de la modalidad en los tratadistas clásicos, pero no obstante las razones que aduce el autor son precisas y acertadas. Boecio

54 Pedro de Osma identifica también las notas que están un tono por debajo de la siguiente, a las cuales denomina sub tonum (fol. 246). Sobre la evolución del principio del movimiento ascendente por semitono y su importancia en las cláusulas que resuelven una consonancia imperfecta en otra perfecta, en la teoría musical a partir del siglo XIV, véase Carl Dahlhaus: Studies on the Origin of Harmonic Tonality, trad. Robert O. Gjerdingen, Princeton University Press, 1990, pp. 73-74, 86-87, passim.

${ }^{55}$ En el caso de llegar hasta doce, se califican de "irregulares".

56 "Las consonancias por donde proceden los modos eclesiásticos son unisonus, tonus, semitonus, diatonus, semiditonus, diatéseron, diapente, hexacor, heptacor, diapasón", pero no son las de los modos boecianos, como discute al detalle Boecio en De institutione musica, IV, según advierte aquí Pedro de Osma (fol. 260v). En la versión en latín, las especies citadas no son diez, sino doce, puesto que la sexta y séptima ("hexacor y heptacor") se dividen en "diapente cum tono, diapente cum semitonio, diapente cum ditono, diapente cum semidítono" (fol. 247v). 
había tomado los nombres de fuentes griegas, en las que estos términos identificaban transposiciones (tonoi) del Sistema Perfecto Mayor de doble octava, no diferentes especies de octava como son los modos eclesiásti$\cos ^{57}$. En el siglo IX, en el contexto de lo que se ha venido a calificar como "Renacimiento carolingio", en el anónimo compendio de teoría conocido como Alia musica se asociaron incorrectamente los mismos términos griegos de Boecio a ocho especies de octava ${ }^{58}$. Aureliano de Réôme, en su Musica disciplina (c. 840) expuso por primera vez el sistema de ocho modos del canto eclesiástico a imagen del oktoechos bizantino ${ }^{59}$, mientras que Hucbaldo de Saint-Amand estableció en su Musica (c. 880, citado en general como De harmonica institutione) la numeración para los ocho modos, distinguiendo entre auténticos y plagales y definiendo las cuatro notas finales ${ }^{60}$. Desde este momento, la asociación entre los nombres boecianos de los modos y los tonos usados en el canto eclesiástico se transmitió sin alteración ni crítica alguna hasta llegar justo a los años

\footnotetext{
${ }^{57}$ El Sistema Perfecto Mayor se componía de cuatro tetracordios consecutivos, a los que se sumaba la nota proslambanomenos un tono por debajo del conjunto (Boecio: De institutone musica, IV.14 y IV.15). Boecio prefiere el término modus, pero también hace una equiparación explícita entre tropus, modus y tonus (De institutione musica, IV.15), tal como hace el mismo Pedro de Osma (fol. 245). Las fuentes boecianas incluyen a Arquitas, Cicerón, Euclides, Filolao, Macrobio, Nicómaco, Platón, Ptolomeo (este se considera en general como el autor del que deriva su teoría sobre los modos). Sobre el complejo problema que representa la relación exacta del tratado boeciano con estas fuentes, véase András Kárpáti: "Translation or Compilation? Contributions to the Analysis of Boethius' De institutioni musica", Studia Musicologica Academiae Scientiarum Hungaricae, 29, 1987, p. 10 y ss. También Calvin M. Bower: "The modes of Boethius", The Journal of Musicology, 3, 1984, p. 255, quien defiende una dependencia principal respecto a Nicómaco, cuyo tratado musical no obstante no se conserva.

58 Alia musica, ed. Jacques Chailley, Paris, Centre de Documentation Universitaire, 1965, p. 107. Véase David E. Cohen: "Notes, scales and modes in the earlier Middle Ages", The Cambridge History of Western Music Theory, Thomas Christensen (ed.), Cambridge University Press, 2002, pp. 331 y ss.; Charles Atkinson: The Critical Nexus, Oxford University Press, 2009, p. 74.

${ }^{59}$ Lawrence Gushee (ed.): Aureliani Reomensis Musica disciplina, Corpus Scriptorium de Musica, 21, Roma, American Institute of Musicology, 1975, VIII, p. 136; aunque el autor no precisa cuáles son los rasgos que definen cada uno de esos modos, sino que los caracteriza de manera cualitativa, empírica. Los orígenes de la clasificación de los cantos del repertorio gregoriano en ocho categorías melódicas (llamados toni en este momento), como ayuda al correcto enlace de los tonos salmódicos con las antífonas consiguientes, se data c. 800 en el contexto de los tonarios redactados por los cantores francos durante la imposición del rito romano en sustitución del galicano. Véase D. E. Cohen: "Notes, scales...", pp. 310 , 317; Michel Huglo: Les tonaires, París, Huegel et Cie., 1971, pp. 29, 445 y ss.; C. Atkinson: The Critical Nexus, pp. 85, 93 y ss. especialmente para la dependencia de las definiciones de los toni en Aureliano respecto a las Etimologías de Isidoro de Sevilla.

${ }^{60}$ Scriptores ecclesiastici de musica sacra potissimum, Martin Gerbert (ed.), St. Blasien, 1784; reimpr. Hildesheim, 1963, vol. 1, p. 119. El título tradicional De harmonica institutione se ha revisado en Yves Chartier: L'Oeuvre Musicale d'Hucbald de Saint-Amand: Les compositions et le traité de musique, Quebec, Bellarmin, 1995, p. 46; Sarah Fuller: "Interpreting Hucbald on Mode", Journal of Music Theory, 1, 52 , 2008, p. 23 y ss. revisa la teoría modal de Hucbaldo, como adaptación de la doctrina boeciana a un repertorio eclesiástico bien establecido. Edward Gollin: "From tonoi to modi: A Transformational Perspective", Music Theory Spectrum, 26, 1, 2004, p. 125, describe la transmisión y alteración del sistema modal griego a la Edad Media y el Renacimiento desde el punto de vista de una serie de transformaciones matemáticas sucesivas del sistema.
} 
que nos ocupan, los centrales del siglo $\mathrm{XV}^{61}$. En el ambiente de la academia humanista en Mantua de Vittorino da Feltre, conocida como "Ca' Giocosa", el cartujo francés Johannes Gallicus (o de Namur, ca. 14151473) se ha considerado el primer autor que se percató de que los modos boecianos formaban parte de un sistema musical de la antigua Grecia, diferente del sistema de los ocho tonos eclesiásticos del canto gregoriano ${ }^{62}$. Gallicus redactó su Ritus canendi vetustissimus et novus entre 1458 y 1464, sin que se llegase a publicar, por lo que su impacto debió ser limitado. Los más importantes e inmediatos teóricos que trataron de los modos no indagan en el tema y hay que esperar hasta la publicación del tratado de Francisco Salinas, en 1577, para encontrar discutida en libro impreso la diferencia entre los modos gregorianos y las harmoniai y los tonoi del sistema griego ${ }^{63}$.

El nuevo tratado de Pedro Martínez de Osma permite rectificar esta narrativa tradicional, pues el texto que estamos presentando se fecha en 1465 y parece muy poco probable que el autor, teólogo en Salamanca, pudiese tener acceso a un texto manuscrito, que nunca se publicó, escrito en Mantua exactamente en los mismos años ${ }^{64}$. Ambos autores, en efecto, razonan contra los errores que mancillan la doctrina musical de sus días, incluso coinciden en denunciar la verbositas de sus oponentes como un error que quieren desterrar ${ }^{65}$. Pero es necesario entender el texto del osmense como

${ }^{61}$ La asociación se extendió a lo largo de la Edad Media incluso asimilando el carácter (ethos) que en la teoría griega clásica se atribuía a cada modo, que los teóricos medievales asignaron igualmente (con notables inconsistencias) a los modos eclesiásticos. Véase Claude Palisca: Music and Ideas, Urbana and Chicago, University of Illinois Press, 2006, p. 79.

62 Vittorino da Feltre poseía, entre su colección de manuscritos griegos, los más importantes textos de Ptolomeo, Porfirio, Arístides Quintilianus o Plutarco. Véase Richard V. Hughes: The Ritus Canendi Vetustissimus et Novus of Johannes Legrense: A Critical Edition with Translation, Introduction and Notes on the Text, tesis doctoral, Glasgow University, 1996. La estancia de Gallicus en la academia de Vittorino es conocida tan solo por la propia mención de este autor, sin más noticia que lo corrobore (ni que certifique por lo demás la enseñanza musical en esta escuela). Véase Anja-Silvia Goeing: Summus Mathematicus et Omnis Humanitatis Pater: The Vitae of Vittorino da Feltre and the Spirit of Humanism, p. 80; Claudio Gallico: "Musica nella Ca' Giocosa", Vittorino da Feltre e la sua scuola: Umanesimo, pedagogia, arti, ed. N. Gianetto, Florencia, Olschki, 1981, p. 191.

${ }^{63}$ Francisco Salinas: De musica libri septem, IV.11-13. Véase C. Palisca: Music and Ideas, p. 90. En 1573, Girolamo Mei redactó su tratado De modis, que no llegó a publicarse y circuló solo en copias manuscritas, en el que analizando las fuentes griegas originales identificaba igualmente la singularidad del sistema modal griego.

${ }^{64}$ El tratado de Gallicus se conserva tan solo en dos copias manuscritas de finales del s. XV: Londres, British Library, Add. 22315 (copiado por su discípulo Nicolas Burtius hacia 1474, fecha del fallecimiento de Johannes Gallicus) y Londres, British Library, Harley 6525. S. Mengozzi: The Renaissance Reform..., p. 184, defiende que Ramos por su parte sí debió conocer el texto de Gallicus, ya en Italia, puesto que en la mano guidoniana que aparece en su Musica practica aparecen insertados los mismos versos de Guido de Arezzo que Gallicus repite hasta cuatro veces en su propio Ritus canendi.

65 Para Gallicus la verbositas es defecto del sistema de solmisación y sus "superfluas" sílabas. Para Pedro de Osma, como se ha dicho, los verbosistas eran aquellos que abusaban de los planteamientos dialécticos en cuestiones de doctrina cristiana. En ambos casos son reflejo de la modernidad que representaba en esos años la oposición a la dialéctica de los siglos anteriores. 
producto original de su agudeza intelectual y su perspicacia, así como de la atención y sincero interés con que se aproximó al texto boeciano ${ }^{66}$. Además, su espíritu crítico, demostrado en su trayectoria personal, le permitió enfrentar la doctrina tradicional acerca de los modos eclesiásticos y el papel que se asignaba al texto normativo en la enseñanza musical, el de Boecio, para llegar a unas conclusiones radicales y pioneras, que tendrán su confirmación fundamentada en el siglo siguiente, también de la pluma de un español, y maestro en Salamanca, Francisco Salinas. En definitiva, a la luz de lo expuesto, nos parece que es tiempo ya de abandonar discursos pertinaces, como el de que la teoría musical española del XV "was largely untouched by humanism" ${ }^{67}$, basados en la ya rebatida idea de una supuesta escasa presencia del humanismo en la Península Ibérica, la cual todavía a fecha de hoy se repite en importantes estudios de alcance internacional.

E) Prevalencia de los sentidos frente al entendimiento al juzgar las consonancias. En este extenso y significativo capítulo final, Pedro de Osma dedica una importante cantidad de espacio a argumentar que el cantante, a quien denomina "armónico", se debe basar en el sentido del oído a la hora de juzgar las consonancias adecuadas, tanto en el canto llano como en el contrapunto. La razón es que los sentidos corporales son los más apropiados para juzgar los fenómenos sensibles que a ellos les afectan, en este caso el oído para juzgar el sonido - como el ojo lo sería para juzgar los colores (fol. 254) ${ }^{68}$. Aquí se diferencia la ciencia "superior", que es la aritmética, la cual debe ocuparse de la proporción como propiedad del número, mientras que por su lado la ciencia inferior ${ }^{69}$ que se denomina "armónica" se ocupa de determinar que, en efecto, la quinta, octava y otras consonancias semejantes son las apropiadas para el canto, sin que le corresponda inquirir qué proporciones numéricas corresponden tales

\footnotetext{
${ }^{66}$ La ausencia de fuentes griegas en su entorno salmantino, que no estarían disponibles hasta el establecimiento de la cátedra de griego en Salamanca en 1495, de la mano de Ayres Barbosa y de Hernán Núñez de Toledo (el Pinciano), y aún sin textos musicales a mano, evidentemente impidió a nuestro autor llevar más allá su argumentación. Véase Luis E. Rodríguez-San Pedro: "Universidad de la Monarquía Católica, 1555-1700”, Historia de la Universidad de Salamanca, Luis E. Rodríguez-San Pedro (coord.), vol. I, Salamanca, Universidad de Salamanca, 2002, p. 120.

${ }^{67}$ Reinhard Strohm: "Fifteenth-century humanism and music outside Italy", The Cambirdge History of Fifteenth Century Music, Cambridge University Press, 2015, p. 272, quien cita a Bonnie Blackburn en este asunto y se remonta hasta las ideas de Robert Stevenson de 1960. Sobre este problema se ha debatido en S. Galán: La teoría de canto de órgano..., p. 39 y ss.

${ }^{68}$ Pedro de Osma referencia esta argumentación concreta a Aristóteles (Física, II.1), un topos que remite al título de la canción Cecus non iudicat de coloribus, presente en el Cancionero Musical de Segovia (n. ${ }^{\circ} 149$ ) sin texto y encabezada por "Ferdinandus et frater eius", aunque concuerda con la pieza Ave ancilla trinitas de H. Isaac, copiada en el manuscrito Q17 del Civico Museo Bibliografico Musicale de Bolonia. También se apoya en la autoridad aristotélica del De anima (II.7, II.8 y II.12) y de Aristoxeno y Ptolomeo según se citan en el tratado musical de Boecio (toda esta argumentación en el fol. 263).

${ }^{69}$ Según se deduce, pues en estos folios el soporte del texto está muy degradado, lo que dificulta (incluso imposibilita) la lectura.
} 
intervalos: esto es "negocio del aritmético", no del cantor o armónico (fol. $262)^{70}$. Es el "sentido corporal" del oído el más cierto a la hora de conocer las voces de cualquier cualidad, como el ojo es quien debe conocer de los colores. De acuerdo con este posicionamiento, Pedro de Osma no discute el aspecto matemático de cuáles deben ser las proporciones numéricas correctas de esos intervalos consonantes.

Pedro de Osma ofrece una conclusión muy interesante, y es que se puede ser "bien diestro en las causas de la música, y saber poco del cantar" y también al contrario. Esto separa los campos de actuación del pensador de aquel del músico practicante, que no necesariamente deben converger en la misma figura, e incluso se podría entender que puede ser deseable que se mantengan separadas. El autor llega a advertir del error que puede suponer creer en todos los razonamientos, como en todos los sentidos, pues dos personas pueden razonar de manera diferente igual que pueden sentir (oír) de manera diferente (fol. 255v) ${ }^{71}$. La argumentación nos remite pues al contexto de la enseñanza práctica de la música en Salamanca, donde se forman diestros cantores antes que pensadores especulativos sobre música ${ }^{72}$.

A lo largo de todo este extenso capítulo final, la autoridad omnipresente que el autor cita de continuo es Aristóteles, a quien ubica sin duda por encima de todos los demás pensadores, incluyendo un especialista en música del prestigio del mismo Boecio. A este le reprocha Pedro de Osma en particular haber seguido en muchas cosas a Pitágoras y a Platón, autores que Aristóteles ya había refutado "en más de mil lugares" (fol. 264). La crítica es especialmente reveladora, puesto que mientras Boecio considera que la facultad "armónica" percibe las cualidades del sonido de manera imprecisa, y necesita de la razón para comprender en su totalidad el fenómeno sonoro, para Pedro de Osma esto no es así exactamente. Admite que el oído no es capaz de percibir las fracciones más diminutas del sonido (comma, etc.), pero defiende la primacía del sentido del oído del cantor o armónico para comprender las consonancias, dejando a los matemáticos la labor de comprender los fundamentos numéricos de tales fenómenos. Años más tarde, Ramos de Pareja seguirá esta misma línea argumental, diferenciando la armonía como unión de voces en concordancia, de la música propiamente dicha, que

\footnotetext{
${ }^{70}$ La lógica que según Pedro de Osma sustenta este razonamiento es la de Aristóteles, tal como aparece en los Analiticos segundos, I:13 (78b34).

${ }^{71} \mathrm{La}$ autoridad a la que remite es Aristóteles, en sus Topicorum, VI, y en "aliis quem locis pluribus". La necesidad de no llevarse a engaño por las "ilusiones de la razón humana", defecto propio de los verbosistas a los que Pedro de Osma combatió en su vida académica, es una constante de su pensamiento. Véase J. Labajos: Escritos académicos..., p. 36.

72 Sobre este asunto, S. Galán: La teoría de canto de órgano..., p. 95 y ss, passim.
} 
incluye conocer la razón de esa misma concordancia, bien estudiada y razonada (Musica practica, I.I.1). En este sentido no hace sino continuar el pensamiento de Ptolomeo y Aristoxeno, tal como lo trasmitió Boecio en su tratado musical ${ }^{73}$. En su texto, no obstante, admite que para los cantantes prácticos es suficiente (al menos de inicio) con saber qué intervalos son consonantes, dejando para más adelante el estudio de los números implicados en las mismas consonancias. El ideal de conjugar el entendimiento musical con la percepción sensorial del oído es, pues, un tema recurrente en el pensamiento musical salmantino que se extiende en el tiempo hasta la obra de Francisco Salinas, pues así lo demuestra el título completo de su tratado musical, que no es otro sino Los siete libros de música, en los que la verdad de su doctrina, por lo que respecta a la armonía como al ritmo, se presenta y demuestra por el sentido y la razón ${ }^{74}$.

\section{Conclusiones}

En conjunto, la argumentación de Pedro Martínez se enriquece y fundamenta gracias a su erudición, que brilla por la profusión de citas concretas a numerosas obras tanto de Aristóteles (Analíticos primeros y segundos, Acerca del alma, Física, Tópicos, Política) como del autor a quien critica y demuestra conocer (Boecio, en De institutione musica, De consolatione philosophae y la Arithmetica). Cabe suponer que el espíritu crítico y minucioso de Pedro de Osma, de haber dispuesto de fuentes griegas originales sobre música, hubiese llevado su razonamiento a extremos de un nivel técnico seguramente apreciable, lo que le hubiera adelantado un siglo a sus sucesores del XVI. De su osadía en el hipotético intento no cabe dudar, pues ya la demostró cuando le fue encargada la revisión de la Vulgata de la catedral salmantina: la cantidad de correcciones que realizó asombró tanto como escandalizó a un auténtico especialista como Antonio de Nebrija ${ }^{75}$.

De la misma manera que Pedro de Osma fue un reformador precoz en el campo de la doctrina de la fe, anticipando actitudes luego propias de innovadores como los erasmistas, en el campo musical aparece asimismo en

\footnotetext{
${ }^{73}$ Boecio: De institutione musica, V.3, donde se explica cómo Ptolomeo reprochaba a Aristoxeno que diese primacía al sentido del oído del armonicus, siendo en cambio lo ideal combinar lo que el oído siente, con lo que el razonamiento matemático aporta acerca del sonido. No hay que olvidar que, en todo caso, Boecio siempre da la mayor importancia al aspecto matemático del entendimiento musical frente a la percepción sensorial de la misma, idea que se halla en la raíz de la posterior y común diferenciación entre musicus y cantor, y la supeditación en los tiempos medievales del segundo frente al primero. Véase András Kárpáti: "Translation or Compilation?...", p. 33.

${ }^{74}$ De musica libri septem, in quibus eius doctrinae veritas tam quae ad harmoniam, quam quae ad rhythmum pertinet, iuxta sensus ac rationis iudicium ostenditur, $\mathcal{E}$ demonstratur.

${ }^{75}$ Sin negar la valía intelectual de Pedro de Osma, que Nebrija situaba solo por debajo de Alonso de Madrigal, el "Tostado". Véase A. de Nebrija: Apología, p. 139.
} 
la línea de pensamiento de los renovadores que arrancan con Johannes Ciconia (c. 1370-1412) y su Nova musica, a inicios del siglo, o el ya mencionado Johannes Gallicus, y que seguirán con los más renombrados exponentes de la nueva teoría en el siglo XVI ${ }^{76}$, Ramos de Pareja, Gafurio o Zarlino. Con los teóricos más "humanistas" Martínez de Osma compartirá la atención a las autoridades clásicas como fuente original de conocimiento, pero sin llegar en ningún caso a introducirse en unas complejidades filológicas para las que no estaba formado y para las que tampoco contaba de medios en su entorno y en su tiempo. La lucha de Pedro de Osma contra los verbosistas que oscurecían el sentido de los textos, se aviene con su intención de aclarar el error de considerar los modos boecianos iguales a los eclesiásticos. También Johannes Gallicus denunciaba la verbositas que enturbiaba con dificultades innecesarias como las sílabas de solmisación. Lo mismo afirmaba Ramos, quien no hablaba de verbositas sino de ambages, término equivalente que también usaba Gallicus. El espíritu crítico de Ramos de Pareja se entronca por tanto directamente con la doctrina salmantina de Pedro de Osma y se enriquece con el contacto con otros autores de su tiempo. Así, la figura renovadora de Ramos aporta el legado de la escuela salmantina a la teoría europea del momento, aunque demasiado pronto $^{77}$. El rechazo que provocaron sus ideas novedosas es bien conocido, y solo en el futuro darán fruto sus planteamientos más radicales, como el abandono del sistema hexacordal de solmisación, la atención a la octava como intervalo generador de los sistemas escalares o su propuesta de un sistema de entonación justa ${ }^{78}$.

Pedro de Osma se revela, en definitiva, como un importante representante a mitad de siglo de una nueva actitud renovadora que, en el marco de un incipiente humanismo musical en toda Europa, dará impulso a los autores que materializarán la renovación de la teoría musical desde la segunda mitad del cuatrocientos y a lo largo del siglo siguiente. A la luz de este nuevo texto cabe considerar, de manera más sólida, la existencia de una particular Escuela de Salamanca de pensamiento musical, que arranca al menos de los años centrales del siglo XV, capaz de combinar una audaz

\footnotetext{
${ }^{76}$ Sobre estos movimientos reformadores en el pensamiento musical del siglo XV véase en especial S. Mengozzi: The Renaissance Reform..., p. 145 y ss. Para el caso español, S. Galán: La teoría de canto de órgano..., p. 40 y ss, passim.

${ }_{77}$ Queda pues fuera de lugar afirmar que la teoría musical de Ramos de Pareja se desarrolló en Italia, como afirma R. Strohm: "Fifteenth-century Humanism...", p. 272.

78 Véase Francisco José León Tello: Estudios de historia de la teoría musical, Madrid, CSIC, 1962 (reimpr. 1991), p. 344 y ss.; J. Javier Goldáraz: Afinación y temperamento en la música occidental, Madrid, Alianza, 1992, p. 40 y ss.; Amaya García: "Francisco de Salinas y la teoría musical renacentista", De Musica libri septem de Francisco de Salinas, Amaya García y Bernardo García-Bernalt (eds.), Salamanca, Ediciones de la Universidad, 2013, p. 68 y ss.
} 
crítica al pensamiento tradicional boeciano con una precisa atención a la práctica musical real y sus problemas. Esta fuente de pensamiento dará al contexto europeo la figura pionera de Ramos de Pareja, el importante grupo de tratadistas del cambio de siglo, y ya en el XVI, figuras capitales de la talla de Francisco Salinas.

Recibido: 8-2-2017

Aceptado: 20-4-2017 